\title{
Long non-coding RNA BANCR regulates cancer stem cell markers in papillary thyroid cancer via the RAF/MEK/ERK signaling pathway
}

\author{
YUANYUAN WANG ${ }^{1,2}$, XIANGDE LIN ${ }^{1}$, XINGHAO FU ${ }^{1}$, WEI YAN ${ }^{1}$, FUSHENG LIN $^{1}$, \\ PENGHAO KUANG ${ }^{1}$, YEZHE LUO ${ }^{1}$, ENDE LIN $^{1}$, XIAOQUAN HONG ${ }^{1}$ and GUOYANG WU ${ }^{1}$ \\ ${ }^{1}$ Department of General Surgery, Zhongshan Hospital, Xiamen University; ${ }^{2}$ Digestive Disease Center \\ of Xiamen University, Affiliated Zhongshan Hospital, Xiamen, Fujian 361004, P.R. China
}

Received September 16, 2017; Accepted June 7, 2018

DOI: $10.3892 /$ or.2018.6502

\begin{abstract}
Thyroid cancer is one of the most common malignant tumors of the endocrine system. Among all thyroid cancers, papillary thyroid carcinoma (PTC) is the most common type. The BRAF-activated non-coding RNA (BANCR) is a 693-bp nucleotide transcript which was first identified in melanoma. However, the role of BANCR in the development of thyroid cancer remains unclear. Therefore, the present study investigated the potential involvement of BANCR in the development of thyroid cancer in vitro using patient tissue samples and a panel of thyroid cancer cell lines, and in vivo using a xenograft mouse model. We observed that BANCR was expressed at a higher level in human thyroid tumor tissues than that noted in the adjacent normal tissues. The expression level of BANCR differed between cultured thyroid cancer cell lines; BANCR expression was lower in the BCPAP cell line than that observed in the CAL-62, WRO and FTC-133 cell lines. Western blot analysis and flow cytometry revealed that overexpression of BANCR in the BCPAP cell line resulted in increased expression of the cancer stem cell markers, LGR5 and EpCAM. Single-clone formation experiments showed that upregulated expression of BANCR in the BCPAP cell line promoted an increase in the number of clones formed. Similarly, in microsphere formation experiments, overexpression of BANCR resulted in increased number and size of microspheres compared with the control cell line. Western blotting experiments showed that BANCR overexpression in BCPAP upregulated the expression of phosphorylated c-Raf, MEK1/2 and ERK1/2. Inhibition of c-Raf via U0126 decreased the expression of LGR5 and EpCAM, as well as phosphorylated levels of c-Raf, MEK1/2 and ERK1/2
\end{abstract}

Correspondence to: Dr Guoyang Wu, Department of General Surgery, Zhongshan Hospital, Xiamen University, 201 Hubin Road, Xiamen, Fujian 361004, P.R. China

E-mail: wuguoyangmail@aliyun.com

Key words: PTC, BANCR, stem cell, LGR5, EPCAM, Raf-MEK-Erk in the BCPAP cells, compared to levels in the DMSO controls. In the xenograft mouse model, BANCR overexpression in the thyroid cancer cells significantly increased tumor growth. Taken together, these results suggest that BANCR plays a role in PTC development by regulating the expression of cancer stem cell markers LGR5 and EpCAM via the c-Raf/MEK/ ERK signaling pathway. Therefore, BANCR may be used as a novel prognostic marker for PTC.

\section{Introduction}

Thyroid cancer is one of the most common malignant tumors of the endocrine system, and its incidence has steadily increased since 1980 (1). Papillary thyroid carcinoma (PTC) accounts for $80 \%$ of all thyroid cancers (2); however, little is known concerning the genetic mechanisms underlying the development of PTC, and no ideal genetic markers for detection have been identified. The primary causes of mortality in PTC patients include local recurrence and distant metastases. Recent evidence indicates that these events occur due to the presence of a specific population of cancer stem cells (CSCs), which exist within various tumor types (3); these are considered the root cause of tumorigenesis, metastasis and recurrence (4,5). Recently, studies utilizing cancer stem cell markers, CD133, CD44, EpCAM, LGR5 and ALDH1, have confirmed the presence of CSCs in lung, breast, pancreatic and prostate cancers (6-9). In our own research, we demonstrated that the self-renewal capacity of CSCs in thyroid carcinoma is associated with the poor prognosis of thyroid cancer patients.

Long non-coding RNAs (lncRNAs) are RNA transcripts approximately 200 nucleotides in length that do not encode proteins, but do function to regulate the expression of related genes (10). IncRNAs are also recognized as regulators of tumorigenesis and tumor progression $(11,12)$. BRAF mutations are the most common genetic lesion found in PTCs, occurring in $45 \%$ of PTCs (13). BRAF-activated lncRNA (BANCR) is a 693-bp transcript found on chromosome 9 and is frequently overexpressed in cancer cells, and has been shown to play a functional role in the migration of melanoma cells (14), and in non-small cell lung cancer where it was shown to promote the migration and invasion of cancer cells through the mitogen 
activated protein kinase (MAPK) signaling pathway (15). Due to the close association between BANCR expression and the proliferation of PTC, the present study investigated the molecular mechanisms underlying the regulation of CSC expression by BANCR in PTC, and the potential regulation through the MAPK signaling pathway.

\section{Materials and methods}

Patients and tissue samples. Tumor samples and paired tissues from 30 patients (20-60 years old, the median age was 35 years and the ratio of females to males was 2:1) who received surgical resection for PTC between 2015 and 2016 at the Department of General Surgery, Zhongshan Hospital, Xiamen University, Xiamen, China were analyzed. All tissue samples were frozen in liquid nitrogen following surgery and then stored at $-80^{\circ} \mathrm{C}$ for future experiments. The study was approved by the Ethics Committee on Human Research of Zhongshan Hospital, Xiamen University, Xiamen and written informed consent was obtained from all patients.

Cell lines and cell culture. The BCPAP human papillary thyroid carcinoma cell line was purchased from the Chinese Academy of Sciences. The normal human thyroid epithelial cell line Nthy-ori 3-1 was purchased from the Chinese Academy of Sciences. Human undifferentiated thyroid carcinoma cell line CAL-62 was purchased from the Chinese Academy of Sciences. The WRO and FTC-133 human follicular thyroid carcinoma cell lines were purchased from Honsun Biological Technology Co., Ltd. (Shanghai, China). All cells were cultured in PRMI-1640 medium (Gibco; Thermo Fisher Scientific, Inc., Waltham, MA, USA), $100 \mathrm{U} / \mathrm{ml}$ penicillin, and $100 \mathrm{mg} / \mathrm{ml}$ streptomycin (Invitrogen; Thermo Fisher Scientific, Inc.) at $37^{\circ} \mathrm{C}$ in $5 \% \mathrm{CO}_{2}$.

Total RNA extraction and quantitative real-time PCR $(q R T-P C R)$. Total RNA from tissues and cells was extracted using RNAiso Plus (Takara Biotechnology Co., Ltd., Dalian, China). RNA was reverse transcribed into cDNA using the PrimeScript RT kit (Takara Biotechnology). The cDNA was amplified using the SYBR Premix Ex Taq II (Takara Biotechnology) control. Relative expression values were calculated by the $2^{-\Delta \Delta C q}$ method to analyze the relative changes in gene expression from real-time quantitative PCR experiments. Primers for qRT-PCR were synthesized by Sangon Biotech (Shanghai, China). The sequences are listed in Table I. The thermocycling conditions for pre-incubation were: $95^{\circ} \mathrm{C}$ for $600 \mathrm{sec}$; for 2 step amplification: $95^{\circ} \mathrm{C}$ for $10 \mathrm{sec}, 60^{\circ} \mathrm{C}$ for $30 \mathrm{sec}(45 \mathrm{X})$; and for melting: $95^{\circ} \mathrm{C}$ for $10 \mathrm{sec}, 65^{\circ} \mathrm{C}$ for $60 \mathrm{sec}$, $97^{\circ} \mathrm{C}$ for $1 \mathrm{sec}$.

Creation of stable cell lines. The BCPAP cell line was infected with a lentiviral vector containing these constructs: BCPAP-NC or BCPAP-BANCR. The BCPAP cell line was infected for $24 \mathrm{~h}$, using a transfection enhancer (Polybrene) at a concentration of $6 \mu \mathrm{g} / \mathrm{ml}$. Transfection efficiency was evaluated using qRT-PCR.

Western blot analysis. Cells were washed twice with cold PBS, lysed with RIPA protein extraction reagent (Beyotime
Table I. Primer sequences.

\begin{tabular}{ll}
\hline Gene & \multicolumn{2}{c}{ Sequences } \\
\hline$\beta$-actin & F: 5'-ACTGGAACTGTGAAGGTGAC-3' \\
& R: 5'-GTGGACTTGGGCGAGGACTG-3' \\
BANCR & F: 5'-CCTTCTTGTAGGGTCTGGATTG-3' \\
& R: 5'-CATTGGTGCTGCAGTCTATTTC-3'
\end{tabular}

F, Forward; R, reverse; BANCR, BRAF-activated non-coding RNA.

Institute of Biotechnology, Shanghai, China), and supplemented with a protease inhibitor cocktail (Roche Molecular Diagnostics, Pleasanton, CA, USA) and phenylmethylsulfonyl fluoride (Beyotime Institute of Biotechnology, Beijing, China). Proteins were denatured at $100^{\circ} \mathrm{C}$ for $10 \mathrm{~min}$ and an equal amount of sample (30 $\mu \mathrm{g})$ was loaded and separated by $10 \%$ sodium dodecyl sulphate-polyacrylamide gel electrophoresis (SDS-PAGE). Proteins were transferred to polyvinylidene fluoride (PVDF) membranes (Millipore, Bedford, MA, USA). The membranes were blocked with 5\% (ECL) chromogenic substrate. The densitometric analysis for the quantification of the bands was performed using enhanced chemiluminescence chromogenic substrate (WesternBright ECL; Advansta, Inc., Menlo Park, CA, USA) and ChemiDoc ${ }^{\mathrm{TM}}$ XRS System (Bio-Rad Laboratories, Inc., Hercules, CA, USA). $\beta$-actin bands were used as an internal reference. The antibodies used in these experiments were purchased from Abcam: E-cadherin (1:1,000; cat. no. 3195S), N-cadherin (1:1,000; cat. no. 13116S), vimentin (1:1,000; cat. no. 5741S), c-Raf (1:2,000; cat. no. 53745S), MEK1/2 (1:2,000; cat. no. 4694S), ERK1/2 (1:2,000; cat. no. 4370S), p-c-Raf (1:2,000; cat. no. 9421S), p-MEK1/2 (1:2,000; cat. no. 2338S), p-ERK1/2 (1:2,000; cat. no. 4370S), GAPDH $(1: 2,000$; cat. no. 5174S) and $\beta$-actin $(1: 1,000$; cat. no. 3700S) (all were from Cell Signaling Technology, Inc., Danvers, MA, USA); secondary antibodies were HRP-goat anti-mouse and HRP-goat anti-rabbit IgG antibody (Jackson ImmunoResearch Laboratories, Inc., West Grove, PA, USA).

Single-clone formation experiment. Cells were digested, suspended, and counted. Cells were uniformly vaccinated to 6-orifice plates containing $2 \mathrm{ml}$ of DMEM culture medium per well, at the following concentrations: 0 cells $/ \mathrm{ml}, 500$ cells $/ \mathrm{ml}$, 800 cells $/ \mathrm{ml}$ and 1,500 cells $/ \mathrm{ml}$, and then incubated at $37^{\circ} \mathrm{C}$ and $5 \%$ volume fraction of $\mathrm{CO}_{2}$. Medium was replaced every 3 to 4 days for approximately 10 days or until clone formation became visible. Clones were fixed using $4 \%$ paraformaldehyde, stained using crystal violet dye solution, scanned (Epson Perfection V370; Epson, Tokyo, Japan) and counted (five random fields were captured and quantified).

Microsphere formation experiment. Cells were suspended in serum-free culture medium at a concentration of $10^{4}$ cells $/ \mathrm{ml}$. Microsphere culture medium [DMEM/F12, B27 (1:50), EGF $20 \mathrm{ng} / \mathrm{ml}$, bFGF $20 \mathrm{ng} / \mathrm{ml}$, insulin $4 \mu \mathrm{g} / \mathrm{ml}$ and $1 \%$ methyl cellulose] was added to 6-wells of an ultra-low adsorption culture plate; no well was placed in the $2 \mathrm{ml}$ medium, and no well was added in the same amount of double resistance. 
A

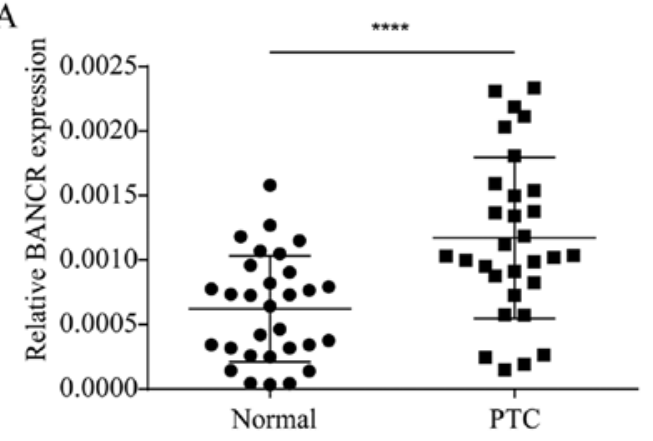

B

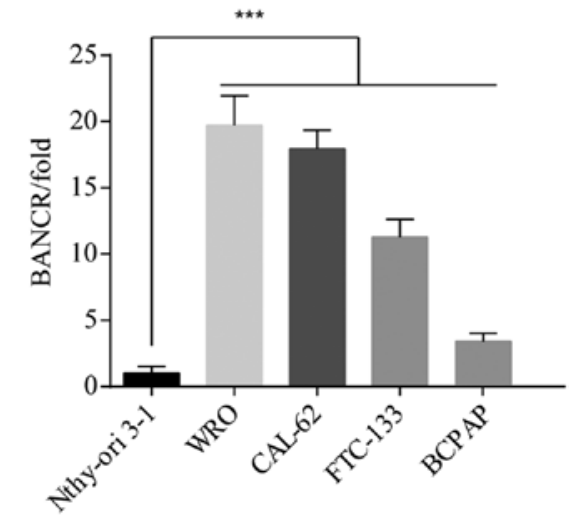

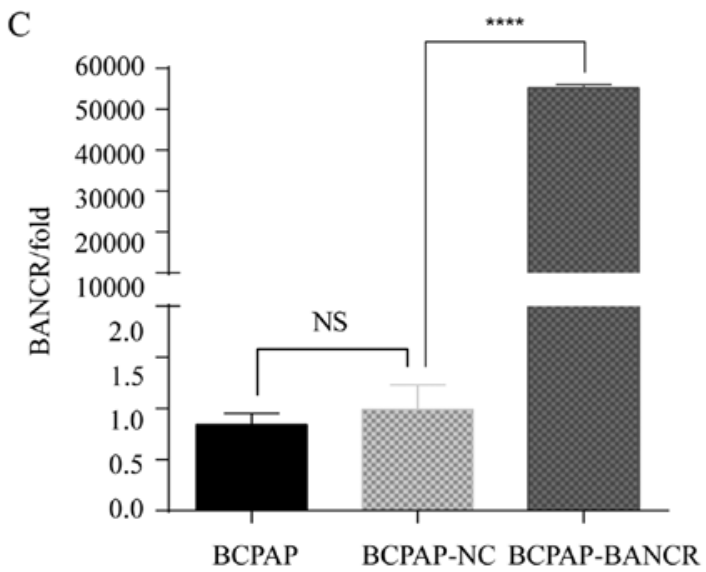

Figure 1. Expression levels of BANCR in PTC tissues, adjacent normal controls and thyroid cancer cell lines. (A) Relative RNA expression levels measured via qRT-PCR. (B) Relative BANCR levels in 4 thyroid cancer cell lines: WRO, CAL-62, BCPAP and FTC-133. (C) Overexpression of BANCR in BCPAP cells using pcDNA-BANCR. Data are means $\pm \mathrm{SEM}, \mathrm{n}=3,{ }^{* * *} \mathrm{P}<0.001 ;{ }^{* * * *} \mathrm{P}<0.0001$; NS, not significant. BCPAP-NC, negative control-transfected cells; BCPAP-BANCR, BANCR-upregulated cells. BANCR, BRAF-activated non-coding RNA.

The cell suspension $(200 \mu \mathrm{l})$ was added to each well of the culture plate, and incubated for approximately 12 days. The cells were observed and photographed using a light microscope (AxioVert.A1; Carl Zeiss GmbH, Jena, Germany), then collected by centrifugation, and the microsphere formation rate was calculated.

Flow cytometry. Cells were suspended using pancreatic enzyme, centrifuged at $200 \mathrm{x}$ g for $3 \mathrm{~min}$, and re-suspended in PBS. Cells were then centrifuged at $300 \mathrm{x} \mathrm{g}$ for $4 \mathrm{~min}$ and re-suspended to a concentration of $1 \times 10^{6}$ cells $/ \mathrm{ml}$ in ice cold PBS. Cells were stained using $5 \mu \mathrm{l} \mathrm{CD133}$ and EPCAM antibody, $2.5 \mu \mathrm{lCD} 44$ antibody, and isotype antibody and incubated in the dark at $4^{\circ} \mathrm{C}$ for $30 \mathrm{~min}$, with oscillation at $15 \mathrm{~min}$. Cells were then washed three times with PBS, re-suspended in PBS, and $400 \mu \mathrm{l}$ of the suspension was added and detection and analysis was carried out using the Beckman FACS Gallios flow cytometer (Beckman Coulter, Inc., Brea, CA, USA).

Tumor formation in mice. Four- to 5-week-old non-pathogenic (SPF) female BALB/c nude mice (18-22 g) were provided by the Shanghai SLAC laboratory Animal Co., Ltd. (SLAC; Shanghai, China). Animal experiments were supported by Xiamen University Laboratory Animal Center (Xiamen, China). The mice were breed under specific pathogen-free conditions with a controlled temperature range from 18 to $29^{\circ} \mathrm{C}$ and a relative humidity of $40-70 \%$ on a 12 -h light/dark cycle. The fodder was sterile and the mice were fed 3 to 4 times/day. Four- to 5-week-old non-pathogenic (SPF) male BALB/c nude mice were divided into one of two groups: the BCPAP NC group and the BANCR-BANCR group. BCPAP stably transfected cell line was harvested, centrifuged and suspended at a concentration of $1.5 \times 10^{7}$ and $2.0 \times 10^{7}$ cells. Each mouse was injected with $100 \mu \mathrm{l}$ of cell suspension via subcutaneous injection and regularly observed. Beginning at day 14 post-injection, tumor length and width were measured by a vernier caliper (PD-151; PRO'SKIT, Shanghai, China) once a week for 5 weeks. At 5 weeks, the mice were sacrificed by cervical dislocation, tumors were measured and photographed, and tumor volumes were calculated $\left(\mathrm{V}=\left(\right.\right.$ length $\mathrm{x}$ width $\left.\left.{ }^{2}\right) / 2\right)$ and plotted on a growth chart. All animal experiments were approved by the Animal Care and Use Committee of the Xiamen University. The ethics code for the approval granted for the animal experiment was xmulac20170375, which was under the supervision of Xiamen University Laboratory Animal Center.

Statistical analysis. All data were analyzed using GraphPad Prism 5.0 statistical software (GraphPad Software, Inc., La Jolla, CA, USA), and the results are expressed as the mean \pm standard error of the mean (SEM). Differences among the groups were assessed by Student's t-test, ANOVA and 
A

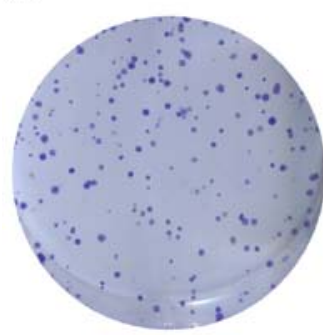

BCPAP-NC

B

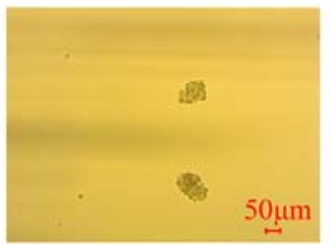

BCPAP-NC

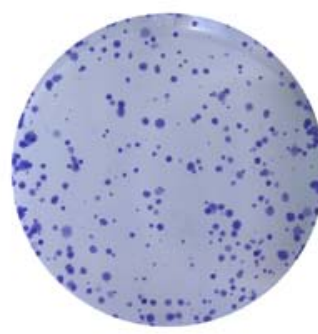

BCPAP-BANCR

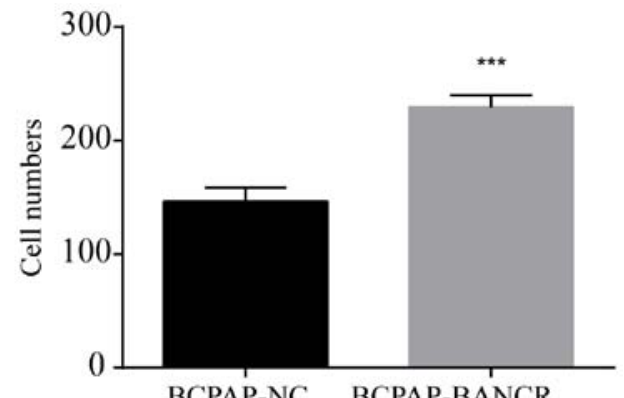

BCPAP-NC BCPAP-BANCR

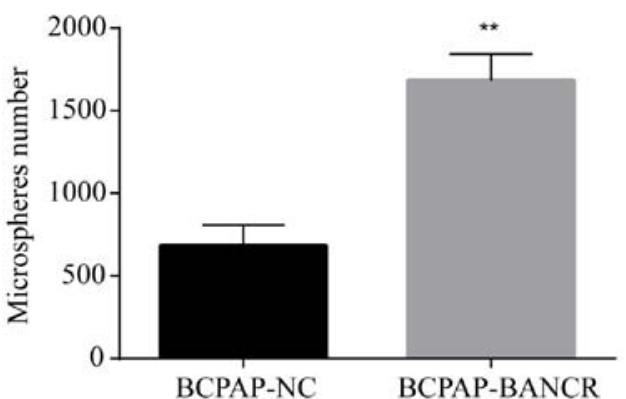

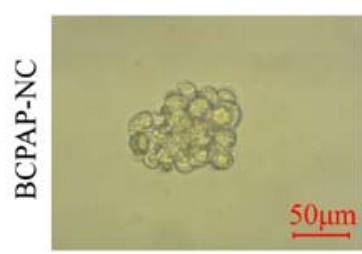
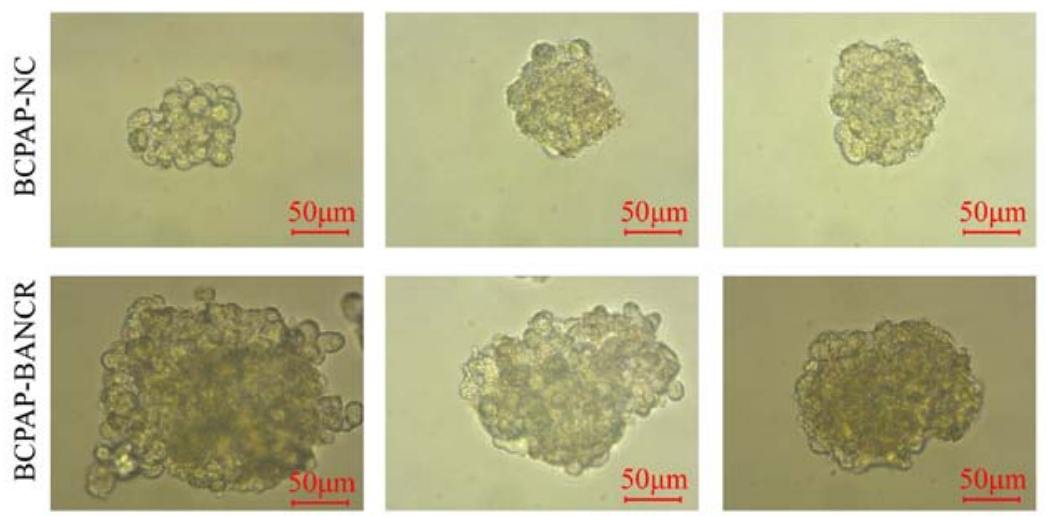

Figure 2. Colony formation and microsphere formation in BANCR-transfected cell lines. (A) Colony number in the control (BCPAP-NC) and BANCRupregulated (BCPAP-BANCR) cells. (B) Microsphere number and size in the control (BCPAP-NC) and BANCR-upregulated (BCPAP-BANCR) cells. Data are means $\pm \mathrm{SEM}, \mathrm{n}=3,{ }^{* * * *} \mathrm{P}<0.001,{ }^{* * *} \mathrm{P}<0.01$. BANCR, BRAF-activated non-coding RNA.

a post-hoc test (Student-Newman-Keuls test). Findings of $\mathrm{P}<0.05$ were considered statistically significant.

\section{Results}

BANCR levels in PTC tissues and cell lines. The expression level of BANCR in 30 paired tissue samples from PTC patients was determined. BANCR expression was significantly higher in thyroid cancer tissues compared to that observed in the adjacent normal tissues $(\mathrm{P}<0.0001)$ (Fig. 1A). In addition, one normal human thyroid epithelial cell line Nthy-ori 3-1 and four human thyroid cancer cell lines that were evaluated exhibited varying expression levels of BANCR $(\mathrm{P}<0.001)$ (Fig. 1B). Therefore, the BCPAP cell line which differed significantly from the other thyroid cancer cell lines with low expression of BANCR was chosen for further experiments. Following transfection with the lentivirus, BCPAP cells (BCPAP-BANCR) showed significant upregulation of BANCR compared with those cells transfected with the empty vector (BCPAP-NC) $(\mathrm{P}<0.0001)$. (Fig. 1C).
$B A N C R$ regulates single-clone formation and microsphere formation. The overexpression of BANCR in the BCPAP-BANCR cell line significantly increased the colony formation ability compared with the BCPAP-NC group $(\mathrm{P}<0.001)$ (Fig. 2A), indicating that cloning ability was significantly promoted by the overexpression of BANCR. Similarly, compared with the control group, upregulation of BANCR expression in BCPAP-BANCR cells significantly increased microsphere number and size $(\mathrm{P}<0.01)$ (Fig. 2B).

BANCR regulates the expression of cancer stem cell markers LGR5 and EpCAM in PTC cells. Upregulation of BANCR in BCPAP-BANCR cells significantly increased expression of the stem cell markers LGR5 and EpCAM, as shown by western blotting (Fig. 3A) and flow cytometry $(\mathrm{P}<0.01)$ (Fig. 3B).

$B A N C R$ regulates the expression of cancer stem cell markers, LGR5 and EPCAM, in PTC cells via the Raf/MEK/ERK signaling pathway. Expression levels of c-Raf, MEK1/2, and ERK1/2 were evaluated in the BANCR-upregulated 
A

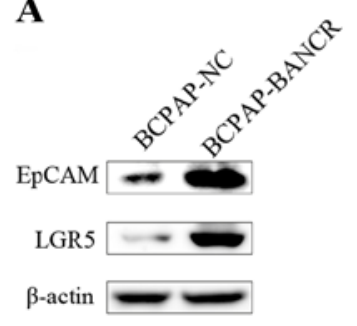

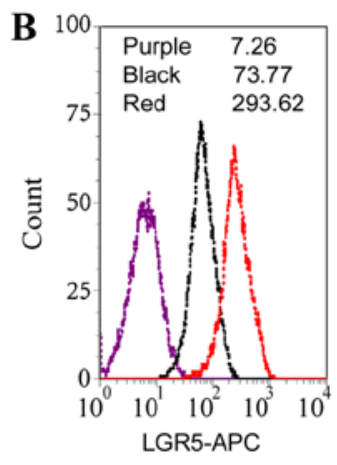
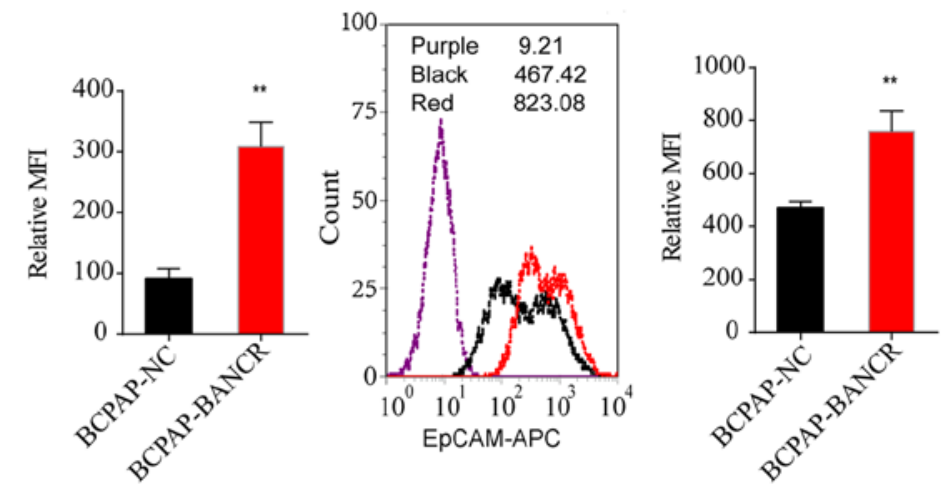

Figure 3. Regulation of LGR5 and EPCAM expression by BANCR. (A) LGR5 and EPCAM expression in control (BCPAP-NC) and BANCR-upregulated (BCPAP-BANCR) cells by western blot analysis. (B) Flow cytometric analysis of LGR5 and EPCAM expression in control (BCPAP-NC) and BANCRupregulated (BCPAP-BANCR) cells. Data are means \pm SEM, $n=3,{ }^{* * *} \mathrm{P}<0.01$. BANCR, BRAF-activated non-coding RNA.
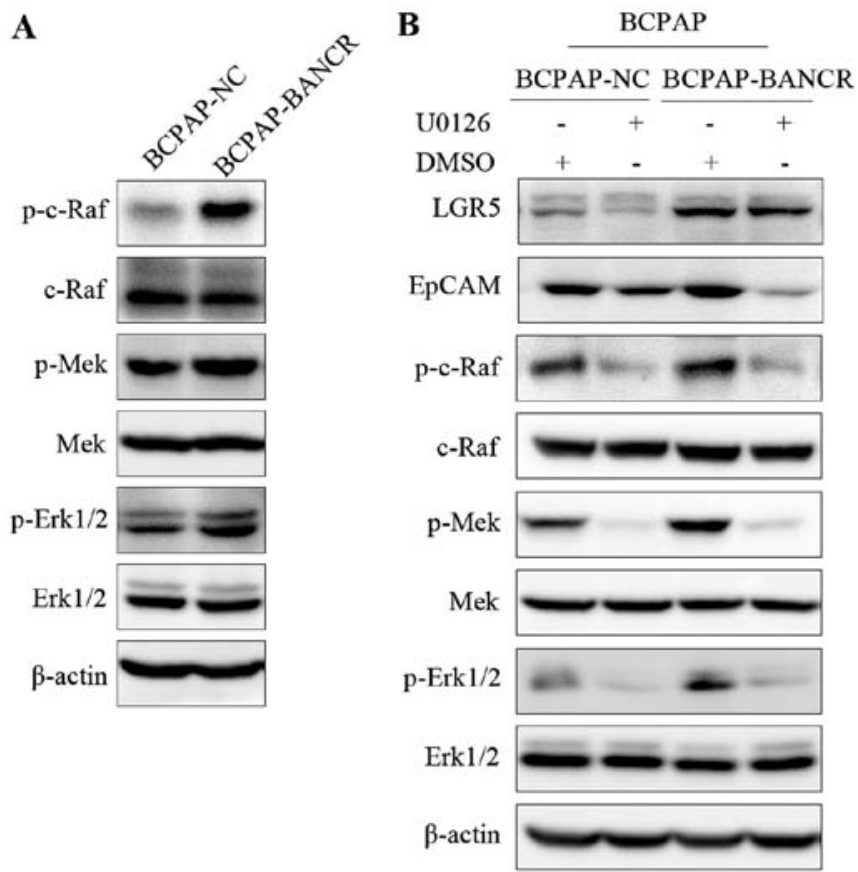

Figure 4. BANCR regulation of LGR5 and EPCAM in PTC cells via the Raf/MEK/ERK signaling pathway. (A) Effect of BANCR overexpression on phosphor (p)-c-Raf, p-MEK1/2 and p-ERK1/2. (B) Effect of U0126 on BANCR-mediated regulation of LGR5, EPCAM, p-c-Raf, p-MEK1/2, and p-ERK1/2 expression in control (BCPAP-NC) and BANCR-upregulated (BCPAP-BANCR) cells. BANCR, BRAF-activated non-coding RNA.

(BCPAP-BANCR) cell line compared to the control BCPAP-NC cell line via western blotting. Expression levels of phospho (p)-c-Raf, p-MEK1/2, and p-ERK1/2 were higher in the BCPAP-BANCR cells than levels noted in the BCPAP-NC cells (Fig. 4A). These results suggest a relationship between BANCR and the Raf/MEK/ERK signaling pathway. To test this hypothesis, we incubated BCPAP cells with the c-Raf inhibitor U0126, which decreased p-c-Raf, p-MEK1/2 and p-ERK1/2 in the BCPAP cell line (Fig. 4B). From this, we concluded that U0126 inhibits the effect of BANCR on the RAF/MEK/ERK signaling pathway. To determine whether the effects of BANCR on the cancer stem cell markers LGR5 and EPCAM are mediated via the Raf/MEK/ERK signaling pathway, the cell line was treated with U0126 and LGR5 and EpCAM protein levels were measured between the two groups using western blot analysis. The results showed that in BCPAP cell lines, the expression of LGR5 and EPCAM was downregulated after the use of U0126, compared to the DMSO controls (Fig. 4B). This result suggests that BANCR regulated LGR5 and EpCAM expression in PTC cells via the Raf/MEK/ERK signaling pathway.

IncRNA BANCR regulates tumor growth in vivo. To investigate the effects of BANCR on PTC cell growth in vivo, we utilized a subcutaneous xenograft mouse model injected with either BANCR-upregulated (BCPAP-BANCR) or BCPAP-NC cells . Results showed that the average tumor size was larger in the BCPAP-BANCR group than that in the BCPAP-NC control group (Fig. 5). The longest diameter exhibited by a single subcutaneous tumor was $11 \mathrm{~mm}$ and no animal presented with multiple tumors. This indicated that tumor formation and growth was promoted by the overexpression of BANCR, and that there is a connection between the expression of BANCR and CSCs.

\section{Discussion}

lncRNAs were long considered to have no function in cells as they do not encode any proteins. However, recent studies have confirmed that IncRNAs play an essential role in normal biological processes such as the regulation of gene expression, and in pathological processes such as tumorigenesis $(16,17)$. Studies have shown that IncRNAs affect many cellular processes in tumor cells, such as cell cycle progression, cell survival, proliferation and migration (18-21).

In thyroid cancer, many IncRNAs are differentially expressed between carcinoma and para-cancer tissue (22). For example, MEG3 (maternal expressed gene 3) was the first lncRNA identified as a tumor suppressor in melanoma cells (23). In PTC, MEG3 is upregulated in carcinoma tissues as compared with normal tissues, and it suppresses cell migration and invasion by targeting Rac1 (24). In addition, PTCSC3 (papillary thyroid carcinoma susceptibility candidate 3 ) is a tumor suppressor in thyroid cancer cells which causes significant growth inhibition, cell cycle arrest and increased apoptosis (25). The lncRNA ANRIL has also been shown to promote the invasion and metastasis of thyroid cancer cells 

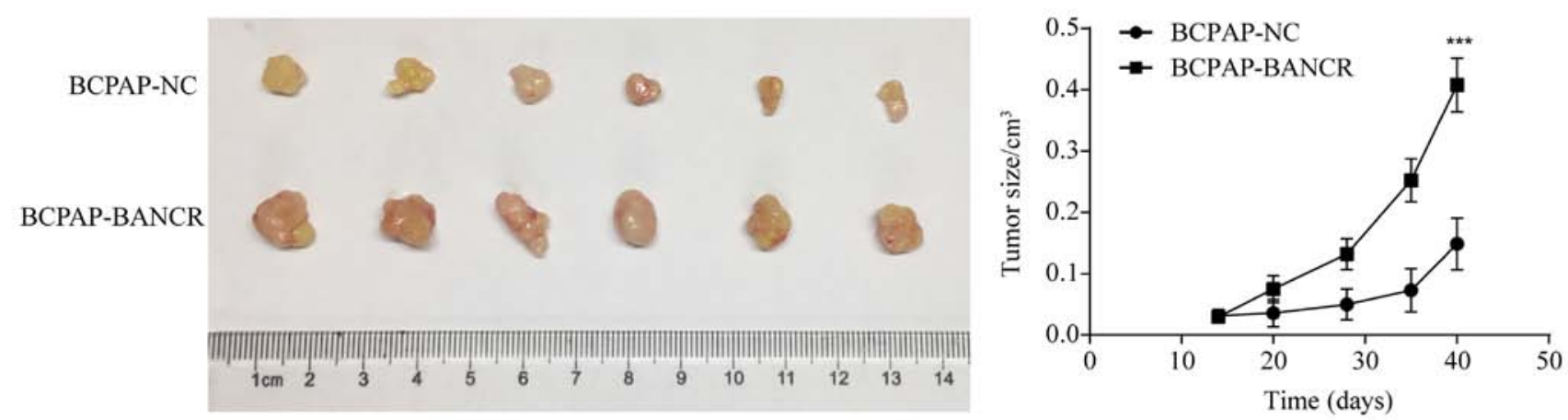

Figure 5. BANCR regulates tumor growth in vivo. Tumor size of tumors derived from BANCR-upregulated (BCPAP-BANCR) and BCPAP-NC cells. Tumor volume $(\mathrm{V})$ was calculated as $\mathrm{V}=\left(\right.$ length $\mathrm{x}$ width $\left.{ }^{2}\right) / 2(39)$. Data are means $\pm \mathrm{SEM} .{ }^{* * *} \mathrm{P}<0.001$. BANCR, BRAF-activated non-coding RNA.

through the TGF- $\beta /$ Smad signaling pathway (26), and nc886 exerts an oncogenic function in thyroid cancer by suppressing RNA-activated protein kinase (PKR) (27).

BRAF-activated non-coding RNA (BANCR) promotes the proliferation of malignant melanoma (14), and was shown to regulate lung carcinoma proliferation and migration via p38 MAPK and JNK inactivation (15). In lung cancer cells, BANCR is associated with poor prognosis and promotes metastasis by inducing EMT (28). Finally, BANCR has been shown to promote cell proliferation in PTC (29).

The characteristics of cancer stem cells include multidirectional differentiation potential, self-renewal ability, multiple drug resistance, and the ability to influence tumor development (5). Therefore, there is increasing evidence that cancer stem cells in tumor tissues may contribute to recurrence in many cancers. Reports have shown that the CSC marker, EpCAM, may be successfully used as a tumor marker in gastric, ovarian, and breast cancer because its high expression in these cancers is closely related to tumor growth, metastasis and advanced tumor stage (30-32). Similarly, increased expression of LGR5 in esophageal cancer and neuroblastoma can enhance tumor cell invasion and migration $(33,34)$. Moreover, studies are underway to determine the relationship between LGR5 and PTC (35). However, little is concerning the regulatory mechanisms involved in the maintenance of EpCAM and LGR5, or whether BANCR is associated with these CSC markers. Therefore, the aim of this study was to investigate these topics.

The present study showed that the expression of BANCR in 30 paired tissue samples from PTC patients was significantly increased compared with that noted in the adjacent normal tissues. Next, utilizing the BCPAP cell line, we found that upregulation of BANCR promoted increased expression of the cancer stem cell markers, LGR5 and EpCAM, in PTC cells. BCPAP was once considered to be a poorly differentiated thyroid gland carcinoma instead of PTC (36). However, in a study investigating papillary and anaplastic thyroid cancers, the author hypothesized that distinct cell phenotypes are governed by different sets of gene master regulators (GMRs). He next proved that anaplastic (8505C) and papillary (BCPAP) TC phenotypes have major differences in cell-cycle pathway and gene networking (37). The two cell lines have different malignant degree, as BCPAP exhibits low-grade malignant in contrast with $8505 \mathrm{C}$. The real origin of the cell line BCPAP is still unclear, based on recent reports and the analysis of the results, we conclude that even if BCPAP is considered to be a poorly differentiated thyroid gland carcinoma instead of PTC, the phenotype of BCPAP is still closer to PTC and we think it is unlikely to affect the outcomes of our study. The result of a single-clone formation experiment showed that upregulated BANCR expression increased the number of clones in the BCPAP cell line. In the microsphere forming experiments, we also demonstrated that overexpression BANCR resulted in an increased number and size of microspheres compared with the control cell line. Additionally, overexpression of BANCR increased the rate of tumor growth as well as tumor size in a xenograft mouse model, suggesting a connection between BANCR expression and CSCs. Thus, this study confirmed that BANCR can regulate the expression of cancer stem cell markers.

In thyroid cancer, there are two classical cell signaling pathways, ERK/MAPK and PI3K/AKT. Studies indicate that the BRAF (V600E) mutation aberrantly activates the MAPK pathway (38). Since BANCR is related to the BRAF V600E mutation, and BANCR regulates lung carcinoma proliferation and migration via the MAPK pathway (15), we investigated the Raf/MEK/ERK signaling pathway. The results showed that c-Raf, MEK1/2, and ERK1/2 were expressed in the BCPAP cell lines, and that phospho-c-Raf, phospho-MEK1/2, and phospho-ERK1/2 were upregulated by overexpression of BANCR. In addition, the effects of BANCR on phospho-cRaf, phospho-MEK $1 / 2$, and phospho-ERK1/2 were inhibited by the c-Raf inhibitor U0126. Furthermore, in the BCPAP cell line, the expression of LGR5 and EpCAM was downregulated after the use of U0126 compared with the DMSO controls. Therefore, we conclude that in PTC cells, BANCR regulates LGR5 and EpCAM expression via the Raf/MEK/ERK signaling pathway. In future research, we plan to expand upon the current study by analyzing CSCs in larger numbers of tissue samples from PTC patients, with the goal of providing new insight into the role of BANCR in PTC.

\section{Acknowledgements}

The present study was supported by the Department of General Surgery, Zhongshan Hospital. The authors wish to thank the Digestive Diseases Center of Xiamen City for equipment support. 


\section{Funding}

No funding was received.

\section{Availability of data and materials}

The datasets used during the present study are available from the corresponding author upon reasonable request.

\section{Authors' contributions}

YW designed the study and wrote the manuscript. XL, XF and WY prepared the figures. FL, PK and YL reviewed the manuscript. EL and XH edited the manuscript. GW agreement to be accountable for all aspects of the work. All authors read and approved the manuscript and agree to be accountable for all aspects of the research in ensuring that the accuracy or integrity of any part of the work are appropriately investigated and resolved.

\section{Ethics approval and consent to participate}

The study was approved by the Ethics Committee on Human Research of Zhongshan Hospital, Xiamen University, Xiamen and written informed consent was obtained from all patients. The ethical code for the approval granted for the animal experiment was xmulac20170375, which was under the supervision of Xiamen University Laboratory Animal Center.

\section{Patient consent for publication}

Not applicable.

\section{Competing interests}

The authors declare that they have no conflict of interests.

\section{References}

1. Chen AY, Jemal A and Ward EM: Increasing incidence of differentiated thyroid cancer in the United States, 1988-2005. Cancer 115: 3801-3807, 2009.

2. Yu W, Wang J, Ma L, Tang X, Qiao Y, Pan Q, Yu Y and Sun F: CD166 plays a pro-carcinogenic role in liver cancer cells via inhibition of FOXO proteins through AKT. Oncol Rep 32: 677-683, 2014.

3. Hoshino Y, Nishida J, Katsuno Y, Koinuma D, Aoki T, Kokudo N, Miyazono K and Ehata S: Smad4 decreases the population of pancreatic cancer-initiating cells through transcriptional repression of ALDH1 A1. Am J Pathol 185: 1457-1470, 2015.

4. Beck B and Blanpain C: Unravelling cancer stem cell potential. Nat Rev Cancer 13: 727-738, 2013.

5. Xiao J, Mu J, Liu T-R and Xu H: Dig the root of cancer: Targeting cancer stem cells therapy. J Med Discov 2: JMD17003, 2017. doi: 10.24262/jmd.2.2.17003.

6. Hermann PC, Huber SL, Herrler T, Aicher A, Ellwart JW, Guba M, Bruns CJ and Heeschen C: Distinct populations of cancer stem cells determine tumor growth and metastatic activity in human pancreatic cancer. Cell Stem Cell 1: 313-323, 2007.

7. Li H and Tang DG: Prostate cancer stem cells and their potential roles in metastasis. J Surg Oncol 103: 558-562, 2011.

8. Pece S, Tosoni D, Confalonieri S, Mazzarol G, Vecchi M, Ronzoni S, Bernard L, Viale G, Pelicci PG and Di Fiore PP Biological and molecular heterogeneity of breast cancers correlates with their cancer stem cell content. Cell 140: 62-73, 2010.
9. Sullivan JP and Minna JD: Tumor oncogenotypes and lung cancer stem cell identity. Cell Stem Cell 7: 2-4, 2010.

10. Ponting CP, Oliver PL and Reik W: Evolution and functions of long noncoding RNAs. Cell 136: 629-641, 2009.

11. Zhu L and Xu PC: Downregulated LncRNA-ANCR promotes osteoblast differentiation by targeting EZH2 and regulating Runx2 expression. Biochem Biophys Res Commun 432: 612-617, 2013.

12. Nakagawa T, Endo H, Yokoyama M, Abe J, Tamai K, Tanaka N, Sato I, Takahashi S, Kondo T and Satoh K: Large noncoding RNA HOTAIR enhances aggressive biological behavior and is associated with short disease-free survival in human non-small cell lung cancer. Biochem Biophys Res Commun 436: 319-324, 2013.

13. Xing M: BRAF mutation in thyroid cancer. Endocr Relat Cancer 12: 245-262, 2005

14. Li R, Zhang L, Jia L, Duan Y, Li Y, Bao L and Sha N: Long non-coding RNA BANCR promotes proliferation in malignant melanoma by regulating MAPK pathway activation. PLoS One 9: e100893, 2014.

15. Jiang W, Zhang D, Xu B, Wu Z, Liu S, Zhang L, Tian Y, Han X and Tian D: Long non-coding RNA BANCR promotes proliferation and migration of lung carcinoma via MAPK pathways. Biomed Pharmacother 69: 90-95, 2015.

16. Flockhart RJ, Webster DE, Qu K, Mascarenhas N, Kovalski J, Kretz M and Khavari PA: BRAFV600E remodels the melanocyte transcriptome and induces BANCR to regulate melanoma cell migration. Cancer Res 73 (Suppl 8): LB-248, 2013.

17. Gupta RA, Shah N, Wang KC, Kim J, Horlings HM, Wong DJ, Tsai MC, Hung T, Argani P, Rinn JL, et al: Long non-coding RNA HOTAIR reprograms chromatin state to promote cancer metastasis. Nature 464: 1071-1076, 2010.

18. Xia M, Yao L, Zhang Q, Wang F, Mei H, Guo X and Huang W: Long noncoding RNA HOTAIR promotes metastasis of renal cell carcinoma by up-regulating histone H3K27 demethylase JMJD3. Oncotarget 8: 19795-19802, 2017.

19. Yang F, Bi J, Xue X, Zheng L, Zhi K, Hua J and Fang G: Up-regulated long non-coding RNA H19 contributes to proliferation of gastric cancer cells. FEBS J 279: 3159-3165, 2012.

20. Yang C, Li X, Wang Y, Zhao L and Chen W: Long non-coding RNA UCA1 regulated cell cycle distribution via CREB through PI3-K dependent pathway in bladder carcinoma cells. Gene 496: 8-16, 2012.

21. Esteller M: Non-coding RNAs in human disease. Nat Rev Genet 12: 861-874, 2011.

22. Lan X, Zhang H, Wang Z, Dong W, Sun W, Shao L, Zhang T and Zhang D: Genome-wide analysis of long noncoding RNA expression profile in papillary thyroid carcinoma. Gene 569: 109-117, 2015.

23. Gibb EA, Brown CJ and Lam WL: The functional role of long non-coding RNA in human carcinomas. Mol Cancer 10: 38, 2011.

24. Wang C, Yan G, Zhang Y, Jia X and Bu P: Long non-coding RNA MEG3 suppresses migration and invasion of thyroid carcinoma by targeting of Rac1. Neoplasma 62: 541-549, 2015.

25. Fan M, Li X, Jiang W, Huang Y, Li J and Wang Z: A long noncoding RNA, PTCSC3, as a tumor suppressor and a target of miRNAs in thyroid cancer cells. Exp Ther Med 5: 1143-1146, 2013.

26. Zhao JJ, Hao S, Wang LL, Hu CY, Zhang S, Guo LJ, Zhang G, Gao B, Jiang Y, Tian WG, et al: Long non-coding RNA ANRIL promotes the invasion and metastasis of thyroid cancer cells through TGF- $\beta /$ Smad signaling pathway. Oncotarget 7 : 57903-57918, 2016.

27. Lee EK, Hong SH, Shin S, Lee HS, Lee JS, Park EJ, Choi SS, Min JW, Park D, Hwang JA, et al: nc886, a non-coding RNA and suppressor of PKR, exerts an oncogenic function in thyroid cancer. Oncotarget 7: 75000-75012, 2016.

28. Sun M, Liu XH, Wang KM, Nie FQ, Kong R, Yang JS, Xia R, Xu TP, Jin FY, Liu ZJ, et al: Downregulation of BRAF activated non-coding RNA is associated with poor prognosis for non-small cell lung cancer and promotes metastasis by affecting epithelialmesenchymal transition. Mol Cancer 13: 68, 2014.

29. Zheng H, Wang M, Jiang L, Chu H, Hu J, Ning J, Li B, Wang D and Xu J: BRAF-activated long noncoding RNA modulates papillary thyroid carcinoma cell proliferation through regulating thyroid stimulating hormone receptor. Cancer Res Treat 48: 698-707, 2016.

30. Dai M, Yuan F, Fu C, Shen G, Hu S and Shen G: Relationship between epithelial cell adhesion molecule (EpCAM) overexpression and gastric cancer patients: A systematic review and meta-analysis. PLoS One 12: e0175357, 2017. 
31. Zheng J, Zhao S, Yu X, Huang S and Liu HY: Simultaneous targeting of CD44 and EpCAM with a bispecific aptamer effectively inhibits intraperitoneal ovarian cancer growth. Theranostics 7: 1373-1388, 2017.

32. Gao S, Sun Y, Liu X, Zhang D and Yang X: EpCAM and COX-2 expression are positively correlated in human breast cancer. Mol Med Rep 15: 3755-3760, 2017.

33. Vieira GC, Chockalingam S, Melegh Z, Greenhough A, Malik S, Szemes M, Park JH, Kaidi A, Zhou L, Catchpoole D, et al: Correction: LGR5 regulates pro-survival MEK/ERK and proliferative Wnt/ $\beta$-catenin signalling in neuroblastoma. Oncotarget 8: 32381, 2017

34. Lv Z, Yu JJ, Zhang WJ, Xiong L, Wang F, Li LF, Zhou XL, Gao XY, Ding XF, Han L, et al: Expression and functional regulation of stemness gene Lgr5 in esophageal squamous cell carcinoma. Oncotarget 8: 26492-26504, 2017.

35. Michelotti G, Jiang X, Sosa JA, Diehl AM and Henderson BB LGR5 is associated with tumor aggressiveness in papillary thyroid cancer. Oncotarget 6: 34549-34560, 2015.
36. Saiselet M, Floor S, Tarabichi M, Dom G, Hébrant A, van Staveren WC and Maenhaut C: Thyroid cancer cell lines: An overview. Front Endocrinol (Lausanne) 3: 133, 2012.

37. Iacobas DA, Tuli NY, Iacobas S, Rasamny JK, Moscatello A, Geliebter J and Tiwari RK: Gene master regulators of papillary and anaplastic thyroid cancers. Oncotarget 9: 2410-2424, 2017.

38. Fraser S, Go C, Aniss A, Sidhu S, Delbridge L, Learoyd D, Clifton-Bligh R, Tacon L, Tsang V, Robinson B, et al: $\mathrm{BRAF}(\mathrm{V} 600 \mathrm{E})$ mutation is associated with decreased diseasefree survival in papillary thyroid cancer. World J Surg 40 1618-1624, 2016

39. Naito S, von Eschenbach AC, Giavazzi R and Fidler IJ: Growth and metastasis of tumor cells isolated from a human renal cell carcinoma implanted into different organs of nude mice. Cancer Res 46: 4109-4115, 1986. 